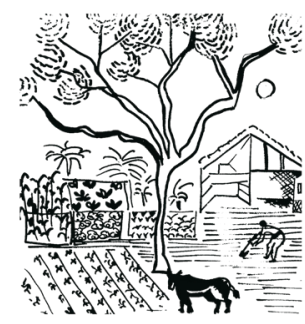

\title{
Transição agroecológica e estilos de agricultura: o caso do Pré-Assentamento Resistência Camponesa
}

Patricia Balbinotti ${ }^{1}$ Vanderlei Franck Thies ${ }^{2}$

\begin{abstract}
Resumo: Este trabalho analisa a experiência de transição agroecológica no Pré-Assentamento Resistência Camponesa (PARC), no município de Cascavel - Paraná. As famílias do PARC convencionaram que a produção agropecuária se daria em duas áreas distintas, podendo ter estilos de agricultura diferentes, mas em uma delas a produção deveria, necessariamente, ser agroecológica. A pesquisa foi realizada através de estudo de caso e os dados obtidos com observação participante e entrevistas. Observou-se que todas as famílias estão envolvidas no processo de transição agroecológica, todavia, nas diferentes áreas, os estilos de agricultura se desenvolvem com base tanto no modelo da agroecologia, como do agronegócio. Também foi observado que as famílias melhoraram sua condição alimentar, desenvolvem experimentação e adotam diferentes práticas agroecológicas. Além disso, ocorre intensa troca de saberes, o que permite o avanço da agroecologia, em que pese as limitações observadas, especialmente a insuficiente recomposição da fertilidade dos solos e a inexpressiva irradiação da agroecologia para o conjunto do PARC.
\end{abstract}

Palavras-Chave: Agroecologia; Assentamento; Estilos de agricultura.

\section{Agroecological transition and farming styles: the Case of Pre-Settlement Peasant Resistance}

ABSTRACT: This paper analyzes the experience of agroecological transition in the Pré-Assentamento Resistência Camponesa (PARC), in Cascavel, Paraná (Brasil). In this pre-settlement collective agreement was agreed that each family should develop agricultural production in two distinct areas, and may have different farming styles, but in one of them the production should necessarily be agroecological. The research was carried out through a case study and the data were obtained with participant observation and interviews. It was observed that all families are involved in the process of agroecological transition, however, in the different areas, the styles of farming are developed based on both the agroecology model and the agribusiness model. It was also observed that families improved their food condition, developed experimentation and adopted different agroecological practices. In addition, there is an intense exchange of knowledge, which potentially allows the future advance of agroecology, in spite of the tensions and limitations observed, especially the insufficient recomposition of soil fertility and the inexpressive irradiation of agroecology to the whole PARC.

KEYWORDs: Agroecology; Settlement; Farming styles.

\footnotetext{
${ }^{1}$ Agrônoma pela Universidade Federal da Fronteira Sul, Campus Erechim-Pontão. E-mail: patriciabalbinotti@hotmail.com ${ }^{2}$ Doutorando em Desenvolvimento pelo programa de pós-gradução em Desenvolvimento Rural pela Universidade Federal do Rio Grande do Sul/UFRGS.E-mail: vftc3@yahoo.com.br
} 


\section{INTRODUÇÃo}

O presente artigo, utilizando a noção de estilos de agricultura, analisa a experiência de transição agroecológica que está sendo realizada pelas famílias do Pré-Assentamento Resistência Camponesa - PARC, no município de Cascavel, região Oeste do Paraná (Brasil). Essa região tem sido marcada historicamente por diversos conflitos pela terra.Também é considerada o berço do agronegócio no estado e, antagonicamente, é onde, em 1984, se funda oficialmente o Movimento dos Trabalhadores Rurais Sem Terra - MST.

A origem do PARC é parte desse contexto de luta pela terra e remonta a ocupação do Complexo Cajati, realizada em 1999, por famílias do MST. Após anos de mobilizações e conflitos, em 2015, ocorre o avanço da negociação do Instituto Nacional de Colonização e Reforma Agrária - INCRA com o proprietário dessa área, com vistas a efetivação de um assentamento. Naquele momento as famílias resolvem renomear o acampamento de Casa Velha para PARC. Atualmente 51 famílias residem na área, ainda vivendo, formalmente, em condição de acampamento, em um contexto agropecuário de forte presença do agronegócio.

Como força econômica e política, o agronegócio busca simbolizar o "moderno", afastando-se da noção negativa do latifúndio (SAUER, 2008), procurando se estabelecer em todos os espaços sociais, inclusive nos assentamentos da reforma agrária. Apesar do modelo de agricultura do agronegócio estar voltado às grandes extensões de terra e produção de escala, as famílias camponesas possuem acesso facilitado a seu aparato tecnológico, dada sua capilaridade e logística, além de sua funcionalidade. Isso gera a incorporação desse modelo de agricultura, de forma mais ou menos intensa, por famílias assentadas, seja via arrendamento das terras, ou pela integração econômica, ou pela introdução do seu padrão técnico-produtivo (ROOS, 2015; BARCELLOS, 2010; GONÇALVES, 2008).

Considera-se que os modelos de agricultura representam os projetos globais de desenvolvimento rural que disputam a hegemonia social e produtiva nos espaços rurais e que, a partir deles, engendram-se diferentes estilos de agricultura, que são as configurações específicas com que os agricultores constituem seus agroecossistemas, mais ou menos alinhados a determinado modelo

No caso do PARC, as áreas de produção foram separadas em duas modalidades, com distintas intencionalidades. Uma delas, denominada pelas famílias de "lotinhos", é destinada para a produção agroecológica e outra, denominada "dois alqueires", é usada com cultivos convencionais. Assim, nessas duas áreas são desenvolvidos estilos de agricultura substantivamente diferentes. A segregação dessas áreas foi uma deliberação das famílias, com base nas orientações políticas do 
MST e visa estimular o avanço da agroecologia no conjunto do futuro assentamento.

Nesse contexto emerge a problemática pesquisada, que analisa a construção de estilos de agricultura alternativos ao modelo do agronegócio que, no caso especificamente estudado, desde 2016, vem sendo construído pelas famílias do PARC. Essas famílias desenvolvem um processo de diálogo e de práticas coletivas voltadas para a transição agroecológica. Buscou-se identificar como vem ocorrendo o processo de construção da agroecologia no PARC e como isso poderá contribuir com o estabelecimento de estilos de agricultura agroecológicos no conjunto do futuro assentamento.

Após essa seção introdutória, em que se define o escopo do estudo, as duas seções seguintes, que possuem caráter teórico, discutem as noções de estilos e modelos de agricultura, apresentando especificamente o entendimento sobre agronegócio, agroecologia e transição agroecológica. Em seguida apresenta-se o método utilizado para a realização da pesquisa e os instrumentos de coleta e análise dos dados. Depois disso, já como resultados da pesquisa, discute-se o significado da agroecologia para o MST e como a estratégia de transição agroecológica foi internalizada e se materializou no PARC. Na seção seguinte apresentam-se as características e as dinâmicas produtivas que envolvem as distintas áreas de produção das famílias do PARC, com ênfase no processo de transição agroecológica. Por fim, são apresentadas as considerações finais.

ESTILOS E MODELOS DE AGRICULTURA: ESPECIFICAÇÃO TEÓRICA E CARACTERIZAÇÃo do AGRONEGÓCIO

Para Schneider e Escher (2014), ao considerar as controvérsias relacionadas ao debate sobre agricultura familiar e campesinato na América Latina, consideram que o conceito de estilos de agricultura representa interessante instrumento heurístico para interpretar as dinâmicas relacionadas aos sujeitos sociais do campo. De forma mais ampla Ploeg (1994) sustenta a relevância do uso da noção de estilos de agricultura como perspectiva metodológica para o estudo das dinâmicas de desenvolvimento rural.

Os estilos de agricultura emergem da capacidade de agência dos agricultores, entendida como as habilidades cognitivas e organizativas desenvolvidas por esses sujeitos, que os habilita a responder de diferentes formas as situações de pressão estrutural geradas pelo processo de crescente mercantilização das dinâmicas sociais e produtivas. Para essa perspectiva analítica, os agricultores são processadores de informações e desenvolvedores de estratégias, em ativa interação com outros atores e instituições, onde, nos mais diversos contextos, agem e reagem mobilizando recursos, visando canalizar seus interesses objetivos e também para incidir sobre a configuração 
dos significados sociais dos eventos (LONG, 2007; LONG; PLOEG, 1994).

Assim, mesmo em situações similares, diferentes agricultores podem configurar uma ampla possibilidade de respostas e estilos de agricultura, o que resulta em grande heterogeneidade nos espaços rurais. A composição dos estilos de agricultura expressa as distintas percepções, interesses e estratégias dos agricultores e, conforme Conterato et al. (2011), representam a diversidade de modos de fazer agricultura a partir das necessidades ou possibilidades dos agricultores organizarem suas relações sociais e produtivas e, também, a partir de diferentes lógicas cognitivas e orientadoras decorrentes da heterogeneidade social que caracteriza os espaços rurais (CONTERATO et al., 2011).

De acordo com Long e Ploeg (1994) a variedade de estilos de agricultura resulta da ligação ou distanciamento, maior ou menor, de determinada forma de fazer agricultura com os diferentes projetos de agricultura pautados em determinado contexto, podendo, por exemplo, expressar maior ou menor internalização do projeto de modernização da agricultura. Conforme Ploeg (2008), o grau de integração aos mercados e a maior ou menor vinculação ao padrão tecnológico dominante são dimensões relevantes para ponderar a vinculação dos estilos aos modelos de agricultura propostos em cada época.

Portanto, os estilos de agricultura, como um fluxo de atividades conscientemente organizadas ao longo do tempo (PLOEG, 1994), representam os projetos que os agricultores constroem, de diferentes maneiras, na interface, simbiótica ou antagônica, com projetos de outros atores. Eles representam um tipo de repertório cultural com o qual os agricultores ativamente gerenciam um conjunto de possibilidades comportamentais como respostas potenciais disponíveis frente às ações de outros atores, podendo incluir desde a modificação, ou a adoção e mesmo a contraposição.

Conforme Niederle et al. (2014) os estilos de agricultura levados a cabo pelos agricultores alinham-se a diferentes perspectivas de desenvolvimento rural, no caso em análise, considera-se que os diferentes projetos de agricultura presentes no PARC são os modelos de agricultura do agronegócio e da agroecologia e que, cada qual, engendra estilos de agricultura distintos. Assim, os modelos de agricultura representam os projetos globais de desenvolvimento rural que disputam a hegemonia das configurações sociais e produtivas nos espaços rurais e os estilos de agricultura são as configurações específicas com que os agricultores constituem seus agroecossistemas, mais ou menos alinhados, aos diferentes modelos em disputa.

O agronegócio é o modelo agropecuário dominante no Oeste paranaense e no Brasil (SAUER, 2008) e os estilos de agricultura que engendra são fundados na incorporação de tecnologia industrial na agricultura e crescente dependência aos 
impérios alimentares, com redução da autonomia dos camponeses e intensificação da mercantilização (PLOEG, 2008), além da ampliação da densidade do capital nos processos de produção agrícola e agroindustrial, elevando a centralidade dos bancos e gerando dependência ao capital financeiro (DELGADO, 2012).

No modelo de agricultura do agronegócio também são configuradas cadeias alimentares longas, com desnaturalização das dietas alimentares, aumento do poder dos supermercados e crescente desconexão entre produtores e consumidores, colocando o controle da alimentação humana global, de forma crescente, nas mãos de reduzido número de grandes empresas privadas (GAZOLLA; SCHNEIDER, 2017). A expansão desse modelo em contexto global tem fragilizado a soberania e a segurança alimentar (ALTIERI, 2010), com persistência da fome e ampliação da obesidade (FAO, 2017), além da insustentabilidade ambiental (GLIESSMAN, 2000).

O uso de agrotóxicos é uma das marcas inocultáveis desse modelo de agricultura, que tem sua gênese vinculada a Revolução Verde, implantada no Brasil, mais intensamente, a partir dos anos 1960. Nos anos 1990 esse modelo se difunde mais intensamente, com a denominação de agribusiness, incialmente associado ao complexo agroindustrial (LEITE; MEDEIROS, 2012), expressando a integração da agricultura com a indústria. Todavia, atualmente, o agronegócio está baseado numa aliança de classes no campo que envolve, especialmente, empresas rurais, grandes transnacionais, o latifúndio e o capital financeiro, contando com apoio de políticas públicas (MARTINS, 2012). Sua matriz tecnológica está voltada para o cultivo de monoculturas, utilizando intensamente insumos químicos e mecanização, além de sementes transgênicas.

O enfoque da análise dirige-se agora ao trabalho das famílias para transformar os estilos de agricultura vinculados ao modelo do agronegócio, em estilos mais coerentes com o modelo agroecológico, ou seja, trata-se do processo de transição agroecológica.

\section{Agroecologia e transiçÃo agroecológica}

A formulação conceitual da agroecologia, em termos internacionais, remonta especialmente os anos 1980, tendo importante contribuição da academia, mas ela nasce muito antes. Ela parte de duas ciências: a ecologia e a agronomia. Ambas andaram distantes, contudo os estudos de ecologia aplicada significaram um passo importante na aproximação dessas duas disciplinas (GLIESSMAN, 2000). Esse autor destaca o aspecto científico e interdisciplinar da agroecologia, sustentando que ela proporciona o conhecimento e a metodologia necessária para a configuração de estilos de agricultura produtivos e economicamente viáveis. 
No Brasil, esse debate se apresenta logo após a ampliação das repercussões dos efeitos negativos dos estilos de agricultura impulsionados pela Revolução Verde, como a redução da biodiversidade, erosão dos solos, exclusão social, concentração de terras, além dos problemas de sustentabilidade (CAPORAL, 2009; WANDERLEY, 2003).

A agroecologia se constitui historicamente como vetor de enfrentamento e resistência dos camponeses a Revolução Verde e, atualmente, ao modelo do agronegócio. De acordo com Altieri (2012, p.104) a ciência da agroecologia "[...] é definida como aplicação dos conceitos e princípios ecológicos para desenhar agroecossistemas sustentáveis [...]”, onde possui grande relevância a abordagem sistêmica do conjunto das questões rurais e também a configuração de agroecossistemas resilientes, que avancem na consolidação de estilos de agricultura que conciliem a produção de alimentos com a conservação ambiental.

A base social da agroecologia é constituída por ampla gama de atores envolvidos na sua construção. Destacam-se os camponeses, que vêm reconstruindo a agricultura de base ecológica, estabelecida através de uma ressignificação na relação homemnatureza e que se consolida com a produção de alimentos livres de agrotóxicos e em estilos de agricultura que demandam baixo uso de insumos externos. Para Leff (2002, p.42) a agroecologia se estabelece como:

[...] um conjunto de conhecimentos sistematizados, baseados em técnicas e saberes tradicionais [...] que incorporam princípios ecológicos e valores culturais às práticas agrícolas que, com o tempo, foram desecologizadas e desculturalizadas pela capitalização e tecnificação da agricultura.

A agricultura ecológica tem sua base material enraizada no conhecimento dos camponeses, nas estratégias de reprodução social que consideram as variáveis ambientais e em manejos agrícolas vinculados à sustentabilidade dos agroecossistemas. Destaca-se o tema dos conhecimentos como algo fundamental nas dinâmicas agroecológicas pois, de acordo com Leff $(2002$, p. 44) “"[...] o saber agroecológico contribui para a construção de um novo paradigma produtivo ao mostrar a possibilidade de produzir 'com a natureza"'.

Nesse sentido, ganha relevo o tema da transição agroecológica, como um processo de mudanças graduais na forma de manejo e gestão dos agroecossistemas (COSTABEBER, 2004), donde se depreende que se trata de um processo lento, de passagem de um modelo de agricultura a outro, com a configuração de novos estilos de agricultura. Cada novo momento determina a ruptura gradual com a base material, cognitiva e tecnológica anterior, para ir assimilando e incorporando os 
processos que se realizam no novo estilo de agricultura. Como destaca Costabeber (2004, p.47), a transição agroecológica não engloba apenas elementos tecnológicos, mas também cognitivos pois:

[...] a ideia de "base ecológica" da atividade agrária se refere a um processo
de ecologização dinâmico, contínuo e crescente através do tempo, e sem ter
um momento final determinado. Este processo de ecologização implica não
somente uma maior racionalização produtiva em base às especificidades
biofísicas de cada agroecossistema, mas também uma mudança de atitudes
e valores dos atores sociais em relação ao manejo dos recursos naturais e à
conservação do meio ambiente.

Portanto, umas das questões fundamentais para o avanço da agroecologia é a decisão a ser tomada pelos agricultores, em relação à configuração dos agroecossistemas, se mais alinhada a estilos de agricultura vinculados ao modelo do agronegócio, ou ao agroecológico. O presente trabalho analisa a construção desse processo de transição, discutindo como a experiência de produção agroecológica dos "lotinhos" incide sobre o avanço da agroecologia nas áreas maiores (dois alqueires) do PARC.

\section{Método}

A pesquisa teve caráter qualitativo, uma vez que trabalhou com o universo das motivações, das aspirações e das atitudes dos sujeitos (MINAYO, 2012), tendo sido realizada através de estudo de caso. Segundo Yin (2001) o estudo de caso apresentase como estratégia mais adequada para a realização da pesquisa, dado que se trata de fenômeno contemporâneo, que não exige controle comportamental e que busca responder questões associadas ao como e ao porquê ocorre determinado fenômeno.

As principais técnicas para a coleta de dados com as famílias de agricultores foi a aplicação de questionário semiestruturado e a realização de entrevistas semiestruturadas com membros da coordenação do pré-assentamento. Além disso, foi realizada observação participante, com anotação em diário de campo, especialmente em reuniões de grupos e outras atividades no PARC. Também foi realizada pesquisa documental, especialmente em documentos do MST, que abordam temas relacionados ao modelo de produção agropecuária e as formas de organização social defendidas pela organização.

O trabalho de coleta dos dados de campo foi dividido em duas fases. A primeira etapa foi realizada durante os meses de julho a setembro de 2017. Nela foram coletadas informações sobre a trajetória e histórico do PARC e buscou-se materiais 
escritos sobre a história da luta pela terra na região Oeste do Paraná. Também foi realizado diagnóstico preliminar dos agroecossistemas das famílias, levantando dados sobre as atividades produtivas e da percepção das famílias sobre essas atividades, tanto nos "lotinhos" como na área de produção de dois alqueires.

A segunda fase da pesquisa aconteceu durante os meses de janeiro a fevereiro de 2018. Nessa fase, a prioridade foi a aplicação do questionário semiestruturado, focado nos objetivos específicos da pesquisa junto às famílias. A partir do cadastro das 51 famílias que vivem no PARC foi realizada a escolha de 15 famílias, através de sorteio, para aplicação do questionário.

A análise do processo de construção da agroecologia no PARC partiu de um conjunto de dados coletados, sistematizados e estruturados em três aspectos principais, que são o social, o produtivo e o organizativo. $\mathrm{O}$ aspecto social buscou identificar os principais traços da composição familiar, para melhor compreensão das características de cada família. No aspecto produtivo, aprofundou-se questões sobre as práticas agrícolas, procurando-se compreender como as famílias vêm realizando a agricultura nas distintas áreas e os significados de cada uma delas. No aspecto organizativo procurou-se identificar as principais potencialidades e dificuldades para o avanço da agroecologia no conjunto das atividades desenvolvidas.

Os dados coletados a partir dessas três dimensões, social, produtiva e organizativa, foram analisados segundo as especificações da transição agroecológica e utilizandose a noção de estilos e modelos de agricultura, apresentados nas seções anteriores. Passa-se a considerar a contribuição do MST no processo de transição agroecológica no PARC, dado ter sido identificado como um dos vetores desse processo.

\section{O MST E A AGROECOLOGIA, OU A AGROECOLOGIA NO MST}

Sem desconsiderar a grande diversidade dos assentamentos de reforma agrária no Brasil e a importância de considerar a heterogeneidade dos espaços rurais, apontado por Carmo et al. (2015), a constante presença do agronegócio nos assentamentos tem gerado fortes contradições internas no MST, dado sua contrariedade política a esse modelo. A reflexão sobre a crise interna vivenciada pelas famílias assentadas, depois da década de 1990, gera uma importante mudança na orientação política do MST em relação aos modelos e estilos de agricultura, expressa na seguinte autocrítica:

1. Adotamos acriticamente um modelo de agricultura convencional e produtivista, que já estava em crise; 2 . reproduzimos a matriz produtiva dominante, com base na monocultura, na produção de commodities para os mercados nacionais monopolizados; 3 . reproduzimos a matriz tecnológica 
convencional com base na química, genética e mecânica, poupadora de mão de obra e demandadora de capital (MST, 2008, p. 90).

Com isso, a partir do início dos anos 2000, o MST assume como linha política a construção da agroecologia em seus espaços, como forma de resistência e ampliação da autonomia das famílias camponesas. Essa inflexão também está associada ao enfrentamento com o agronegócio e as políticas neoliberais da época, além da internacionalização da organização, com a entrada do MST na Via Campesina Internacional. A Via Campesina é um movimento internacional de agricultores que congrega 182 organizações de 81 países e tem se notabilizado por suas ações em defesa do modo de vida camponês, da soberania alimentar, da agroecologia e dos territórios camponeses, bem como por suas críticas ao modelo de agricultura do agronegócio (GUHUR, 2010).

A agroecologia no MST é inserida através de longo processo de debates internos e críticas ao modelo e aos estilos de agricultura levada a cabo em muitos assentamentos. A partir do IV Congresso Nacional do movimento, em meados dos anos 2000, o MST fomenta as discussões em torno da agroecologia, que passa a ser a referência técnica e modelo de agricultura para os assentamentos. Esse processo, de amadurecimento da crítica ao modelo de agricultura do agronegócio, de autocrítica em relação a muitos estilos de agricultura desenvolvidos nos assentamentos e da definição por uma nova perspectiva produtiva de agricultura, segue em curso, sendo o processo de transição agroecológica do PARC parte desse processo maior que é impulsionado pelo MST.

O entendimento do MST sobre o modelo agroecológico aponta que ele é muito mais do que apenas a ecologização das práticas agrícolas. Ele envolve também as práticas sociais, as relações entre as pessoas, que condicionam múltiplas relações com o ambiente e com a sociedade. Estas ações motivam a construção de novos significados sociais e produtivos, além do resgate de conhecimentos sobre a natureza e a valorização de um ser humano com mais humanidade. Envolve, em termos mais amplos, conforme Martins (2012), processos que contribuem para romper-se com a alienação humana, pois as práticas sociais, organizativas e produtivas, englobadas na concepção do modelo de agroecologia do MST, são interconectadas com a luta pela emancipação dos camponeses contra o capital.

Deste modo, o MST passou a impulsionar a agroecologia dentro dos seus espaços de incidência, bem como nas instâncias organizativas, incorporando essa temática de forma intensa em suas redes de articulações, ampliando o diálogo e o intercâmbio com diversas outras entidades que também fomentam a agroecologia. Além disso, o modelo da agroecologia passa a ser gradualmente incorporada nas escolas 
onde estudam os jovens filhos(as) de assentados e nas quais o movimento possui alguma capacidade de incidência, além da constituição de centros de educação em agroecologia do próprio MST. Essa incidência, em favor da agroecologia, também alcança os assentamentos e as famílias camponesas, onde se passou a estimular fortemente o resgate, a difusão e a vivência de saberes e práticas agroecológicas.

Nesse sentido, a ação do MST se constitui como um vetor de estímulo as famílias do PARC à adoção do modelo da agroecologia e a configuração de estilos de agricultura que rompam com o modelo do agronegócio. Esse processo é analisado de forma específica nas seções seguintes.

\section{CaracterizaÇÃo do PARC e A EMERgênCIA da transição AGroecológica}

A ocupação do Complexo Cajati ocorreu no dia 19 de maio de 1999, no município de Cascavel. Depois de 15 anos de disputas e tensões, em 2015, ocorre uma alteração significativa na vida das famílias acampadas, quando ocorre avanços na negociação da área entre o INCRA e o proprietário da terra. Atualmente existem 51 famílias morando no PARC, em condição de acampamento. A área total destinada ao préassentamento é de 960 ha, sendo 528 destes destinados a reserva legal. Atualmente a área segue em negociação entre o INCRA e o proprietário. Nos últimos dois anos (2016 a 2018), esse processo sofreu forte estagnação.

As famílias do PARC atualmente estão divididas em quatro grupos, com aproximadamente 13 famílias cada. Esses grupos de famílias compõem a forma de organização preconizada pelo MST, onde cada grupo realiza reuniões semanais, discussões e tomada de decisões sobre aspectos importantes e cotidianos do conjunto da área e das famílias. As demandas dos grupos são discutidas e encaminhadas nas reuniões da coordenação do PARC e, em caso de necessidade, são apreciadas novamente em assembleia com todas as famílias do pré-assentamento.

O processo organizativo dentro do PARC estimulou reflexões e estabeleceu decisões coletivas, onde se canalizou e amadureceu a orientação do MST de produzir de forma agroecológica em uma parte da área. Como descreve um dos dirigentes do PARC "A ideia de começar a plantar agroecológico, aos poucos, pra ir adquirindo experiência, conhecendo e entendendo." Esse depoimento evidencia a capacidade de agência dos sujeitos, individual ou coletivamente, como elemento central da ação humana (LONG, 2007), pois as famílias do PARC atuam intensamente no processamento de informações, bem como na definição e operação de estratégias e de ações no ambiente econômico, social e ecológico onde estão inseridos.

Nessa perspectiva, as decisões e ações das famílias do PARC, como atores sociais, são expressas e materializadas na intencionalidade de constituir um processo 
de transição agroecológica, definida por Costabeber (2004, p.47) “[...] como o processo gradual de câmbio através do tempo nas formas de manejo e gestão dos agroecossistemas".

Das 15 famílias entrevistadas, nove, chegaram ao PARC entre os anos de 2004 e 2012. As mais recentes, seis no total, chegaram entre os anos de 2015 e 2016. Das famílias pesquisadas, três eram compostas por somente um membro. No conjunto das famílias observou-se a presença de: sete crianças, sete jovens, 18 adultos e oito idosos. O grau de escolaridade predominante entre adultos e idosos é o ensino primário, o que demostra baixo nível de escolaridade. Entre os idosos, nenhum superou esse estágio escolar e o ensino superior foi alcançado por apenas um residente do PARC. É importante destacar que, atualmente, todas as crianças e jovens residentes no PARC, que estão em idade escolar, frequentam a escola.

Cerca de metade das famílias consultadas relataram que tiveram as primeiras discussões e contato com agroecologia no PARC. Isso demostra a importância do processo que se vem constituindo dentro dessa área, mas, ao mesmo tempo, estabelece um desafio ainda maior, de se ir construindo o conhecimento, não somente técnico com essas famílias, mas também organizativo e político, que dê sustentação a tomada de decisão favorável a adoção do modelo agroecológico. Aí o papel da organização interna no PARC e a contribuição do MST parece jogar papel decisivo, como ressalta Martins (2017, p. 185) "[...] é nesta decisão singular que a nova estratégia do MST influi [...]”. O estudo de Gonçalves (2008) vai na mesma direção, apontando a relevância do trabalho do MST para impulsionar processos de transição agroecológica.

Essa incidência do MST na decisão individual das famílias também aparece em uma dimensão mais geral do processo. Assim, outro vetor importante que impulsiona o avanço da agroecologia, que está sendo levantada nas instâncias do PARC, é que o avanço no processo de negociação da área, que está sendo condicionado a produção do futuro assentamento ser integralmente agroecológica. Como destaca um dos dirigentes do setor de produção do MST

[...] nós fizemos trabalho de formação, com a frente, com a coordenação, da importância da produção agroecológica, orgânica, e isso junto fizemos vários trabalhos com a comunidade em si, com as famílias da importância da produção. Como aqui a proposta de desapropriação, da área aqui, a proposta é ter os lotes com produção agroecológica, é um dos motivos muito fortes pra desapropriação dessa área. Então, as famílias que vieram de outros acampamentos, avaliados pra essa área, e as famílias que permaneceram aqui, que já eram desse local, já estão com esse compromisso, que tem que 
produzir orgânico/agroecológicos nos nossos lotes, ou parte dele. Então, nós partimos dessa ideia, então por que esperar ir para os lotes? Então, por que nois já não começa uma experiência desde já? (Entrevistado A1, 2018).

Para Guzmàn (2001) o núcleo central da proposta teórica e metodológica da agroecologia não reside em levar soluções para as comunidades, mas deve-se identificar as possibilidades de solução existentes localmente e tratar de animar os processos de transformação, através de dinâmicas participativas e da potencialização das formas de ação social coletiva, a exemplo do que se observou entre as famílias do PARC. Essa questão metodológica, de valorizar os conhecimentos locais e a participação dos agricultores, se coloca para a pesquisa e a extensão rural como um dos grandes desafios contemporâneos no trabalho de impulso a agroecologia, como também apontam os estudos de Carmo et al. (2015) e Lopes et al. (2017).

Foi no âmago do diálogo coletivo que amadureceu, entre as famílias do PARC, a ideia de constituir uma estratégia de transição agroecológica fundada na divisão dos lotes em duas áreas distintas ("lotinhos" e dois alqueires). Nesse contexto, a definição de fazer e a implantação dos "lotinhos", em 2016, é compreendida como uma estratégia para catalisar a agroecologia. A estratégia de produção dessas pequenas áreas está vinculada a diversos fatores, como a produção de alimentos para consumo das famílias, de aprendizagem dos processos ecológicos, de uso de insumos locais, da construção coletiva e da troca de saberes dos processos vivenciados pelas famílias, ou seja, a configuração de estilos de agricultura vinculados ao modelo agroecológico, tudo isso perpassando e permeando pelas instâncias do PARC.

\section{As dinÂMicas Produtivas e a transição agroecológica no PARC}

A área de produção dos dois alqueires (4,8 ha por família) foi constituída logo após o surgimento do acampamento, ainda no ano 2000. Sempre esteve ligada às discussões e decisões coletivas no PARC. A produção dessas áreas é destinada principalmente à venda, para obtenção de renda, mas parte da produção também é utilizada na alimentação das famílias e de seus animais. Das 15 famílias consultadas, duas não cultivam essas áreas, pois uma possui ocupação externa ao PARC e a outra, por não permanecer em tempo integral no pré-assentamento.

Nessas áreas a maioria dos cultivos são convencionais, contudo, não se permite cultivos transgênicos. Os dados levantados apontam que $86 \%$ das famílias desenvolvem cultivos convencionais nessas áreas. Os principais cultivos são feijão, mandioca, arroz e, especialmente milho, todos na forma de monocultivos e com utilização de insumos químicos industrializados e externos a unidade de produção. 
Utiliza-se intensamente a mecanização ( $70 \%$ das famílias), com contratação de máquinas para realização das operações agrícolas, do plantio até a colheita. Além disso, $70 \%$ das famílias utilizam agrotóxicos nessas áreas. Fica evidente que, nessas áreas desenvolvem-se estilos de agricultura vinculados ao modelo do agronegócio.

Por outro lado, as sementes de milho e feijão, na sua maioria, são adquiridas com vizinhos, ou guardadas de um ano para outro pela própria família. Cerca de um terço das famílias utilizam tração animal, principalmente para limpar as entre linhas nas culturas do milho, mandioca e feijão, evitando o uso de agrotóxicos. Assim, nas áreas dos dois alqueires, existem famílias que mesclam práticas de produção convencionais e agroecológicas. Esse tipo de convivência, entre estilos de agricultura agroecológicos e convencionais, também foi destacado por Gonçalves (2012, p.16) ao afirmar que "É verdade que existem os produtores que mesclam práticas agroecológicas com práticas convencionais, ações que futuramente podem ampliar e até desencadear uma transição eminentemente agroecológica".

A área destinada aos "lotinhos" equivale a 0,3 hectares por família e seu cultivo é focado na produção agroecológica, tendo como orientação coletiva que todos devam cultivar a área, principalmente, para autoconsumo. A definição por realizar essa experiência foi tomada em 2016, quando se apresenta objetivamente a possibilidade de o acampamento constituir-se em assentamento.

Com a destinação dessa área para cultivos agroecológicos as famílias incorporam o sentido da produção e consumo de alimentos de qualidade, implantando uma diversidade de culturas. Por exemplo, mandioca e feijão, que são cultivados por quatorze das quinze famílias entrevistadas e o arroz, que é cultivado por onze famílias, são produtos importantes na dieta destas famílias. Entre 60 e $80 \%$ das famílias cultivam milho nos lotinhos (para consumo familiar e dos animais), amendoim, abóbora e batata-doce. Além desses, em menor proporção de famílias, também são cultivados: caxi, caramoela, alho, quiabo, ervilha, melancia, pepino, cebola, inhame e chuchu. $\mathrm{O}$ fato desses últimos produtos serem cultivados por menor número de famílias revela um limite da experiência, mas, ao mesmo tempo, expressa a potencialidade de ampliação da diversidade de cultivos alimentares que podem ser desenvolvidos pelas famílias na área dos lotinhos.

Ao ser questionado sobre a importância dessa experiência, um dos elementos que aparecem em destaque nas falas dos entrevistados é o prazer em ter a produção para autoconsumo, onde se enfatiza a qualidade dos alimentos consumidos. Como relata o entrevistado nove "É importante, porque tiramos muito alimento saudável, pro gasto".

Estas são duas dimensões relevantes a considerar na experiência estudada, 
a qualidade e a diversidade dos alimentos produzidos, que contribuem para assegurar a segurança alimentar das famílias, que assim resgatam e fortalecem o papel camponês da produção de alimentos saudáveis. A dimensão da importância alimentar dos lotinhos também é destacada pela entrevistada seis, quando afirma que "[...] muito importante por que, ali as famílias conseguem produzir para o consumo e também aprender trabalhar os produtos orgânicos”. Destaca-se na fala dois elementos fundamentais da experiência dos lotinhos, que são: a produção para a alimentação familiar, que foi fortemente estimulada e os aprendizados agroecológicos, que as famílias estão construindo com a experiência.

Observa-se que o trabalho nos lotinhos têm servido como referência para a produção de alimentos e para a produção orgânica, especialmente com a perspectiva da efetivação do assentamento, como destaca o entrevistado 14 " [...] é bom porque o pessoal vai pegando o jeito realmente [...] é uma experiência muito boa dos lotinhos, pra depois irem bem seguros para o lote definitivo, pra cultivar, no caso, tudo orgânico." Desta fala, também pode-se destacar os aprendizados que as famílias vêm construindo com a experiência, o que, de acordo com Leff (2002), possibilita que os saberes agroecológicos se forjem entre as teorias e práticas camponesas, se configurando em um novo campo de saberes práticos para uma agricultura mais sustentável, como uma ferramenta da segurança alimentar das famílias.

Dentre as principais atividades de capacitação sobre agroecologia que as famílias participaram, a maioria ( $73 \%$ das entrevistadas) declara que participou, ou participa anualmente, das Jornadas Paranaenses de Agroecologia - JPA. Este é um encontro dos camponeses e camponesas para a promoção, divulgação e trocas de saberes em agroecologia, realizado anualmente em diferentes regiões do Paraná. Este espaço também se mostrou importante na obtenção e troca de sementes entre os participantes, pois no último dia do encontro ocorre a partilha de sementes. Muitas dessas sementes partilhadas foram plantadas no PARC, especialmente de milho e feijão.

Segundo os entrevistados, além da participação nas JPA, a capacitação das famílias em agroecologia também ocorreu através de: reuniões do grupo da Rede Ecovida, oficinas sobre caldas para controle de doenças e pragas, que ocorreram no acampamento, festa das sementes e a participação no grupo dos orgânicos do PARC. A Rede Ecovida de Agroecologia garante a certificação de produtos orgânicos, através de certificação participativa. Sua criação ocorreu no ano de 1998, através de ONGs e organizações de agricultores construídas na região sul do Brasil. Atualmente conta com 27 núcleos regionais, abrangendo cerca de 352 municípios, 340 grupos de agricultores (envolvendo cerca de 4.500 famílias) e 
vinte ONGs. Em toda a área de atuação da Ecovida acontecem mais de 120 feiras ecológicas e ainda outras formas de comercialização.

Ao que se pode perceber nos depoimentos das famílias, um dos principais momentos coletivos de reflexão e aprendizado sobre agroecologia ocorre no grupo de orgânicos do PARC, em que participam 27 famílias. Esse grupo integra o Núcleo Oeste da Rede Ecovida. O grupo de orgânicos do PARC foi criado em 2016, com intuito de fomentar a produção de alimentos ecológicos e viabilizar a certificação da produção orgânica para fins de comercialização. A participação das famílias é voluntária, portanto, observou-se que este grupo é instrumento coletivo de debates e acordos sobre a produção, com intuito de regularizar a certificação da área dos lotinhos e estimular o processo de transição agroecológica. Como ressalta um dos membros da coordenação do PARC:

[...] outra ação que foi determinante também é a questão do grupo orgânico, foi criado pra ter o selo de orgânico, por que não basta só produzir orgânico, pra sociedade se não tiver o selo, não tiver o que vá garantir o que você está produzindo. Só sua fala não vale, então foi uma das ações importantes, pra que as famílias entrassem. A aderência ao grupo orgânico foi muito boa, muito satisfatória na verdade. [...] foi feito a partir da discussão em assembleia, na coordenação, no setor de produção, e a aderência das famílias foi grande, surpreendente na verdade. (Entrevistado A1, 2018).

Dentre os manejos agroecológicos que as famílias experimentaram e utilizam mais intensamente, destaca-se o uso das sementes crioulas e diversas caldas, mas também o uso de adubação verde e orgânica, cobertura morta e policultivos. Conforme Altieri (2012), esse processo de aprendizado teórico e experimentação prática realizado pelos agricultores constitui um dos fundamentos do avanço do modelo agroecológico.

A perspectiva da agroecologia se expressa no potencial produtivo que vem se construindo na área de produção dos lotinhos e nas discussões do MST. Em que pese não se verificar, até o momento, a irradiação, ou um "transbordamento" significativo da agroecologia para as áreas de dois alqueires, fica evidente que a transição está em curso, de acordo com o afirmado por Costabeber (2004), como um processo de ecologização dos agroecossistemas, que é dinâmico e contínuo através do tempo.

O avanço da transição agroecológica também se expressa na possibilidade de comercialização dos produtos agroecológicos no município de Cascavel, o que se apresenta como um novo desafio às famílias do PARC. Essa frente de 
trabalho, da construção social de mercados locais, através de cadeias curtas, ou redes alimentares alternativas, como o destacado por Gazolla e Schneider (2017), é parte constituinte do processo global de avanço e consolidação do modelo da agroecologia.

Nesse sentido, o avanço da transição agroecológica também é evidenciado pela entrega de alimentos produzidos pelas famílias do PARC para o Programa Nacional de Alimentação Escolar (PNAE), em Cascavel. Essa ação é viabilizada formalmente pela COOPERCAF (Cooperativa de Produção e Comercialização e Agricultura Familiar), que é uma cooperativa regional das famílias assentadas, fundada em 2001, que trabalha especialmente com processos de comercialização da produção agropecuária, abrangendo assentamentos de diferentes municípios da região Oeste do Paraná. Isso tem estimulado a produção de alimentos dos lotinhos para a entrega na Cooperativa, abrindo-se assim a possibilidade da ampliação da produção agroecológica, também para a comercialização.

Por outro lado, um dos importantes limites da experiência, revelado pela pesquisa, está associado a deficiente recomposição da fertilidade dos solos nos lotinhos. Constatou-se que apenas um quarto das famílias realizam adubação orgânica (utilizando esterco bovino, cama de aviário e adubo orgânico peletizado), apenas um terço das famílias realizam consórcio de culturas e somente um quinto das famílias realizam adubação verde. Portanto, os procedimentos agronômicos de manutenção da fertilidade dos solos, ainda que identificados com estilos de agricultura vinculados ao modelo agroecológico, são insuficientemente praticados pela maioria das famílias, o que poderá esgotar a capacidade produtiva dos agroecossistemas e comprometer seriamente o desenvolvimento dos cultivos. Se não forem tomadas medidas para fazer frente a esse estrangulamento, ele possivelmente passará a comprometer o conjunto da experiência.

Um sinalizador dessa fragilidade é o fato de que a prática agroecológica mais acionada pelas famílias é a utilização de caldas, muitas vezes com caráter corretivo, que é realizada por $80 \%$ dos entrevistados. Além disso, o ataque de insetos é tido como o segundo maior problema no cultivo dos lotinhos, sendo apontado por $30 \%$ dos entrevistados. Esses ataques podem estar associados à deficiência nutricional das plantas, bem como a desequilíbrios no microambiente dos lotinhos, ou de seu entorno.

A principal dificuldade, apontada por cerca de metade dos entrevistados, para o cultivo nos lotinhos, diz respeito às capinas que precisam ser realizadas, principalmente no verão, pois elas exigem certo tempo, mão de obra e esforço físico. A maior parte das famílias cultivam grãos e essas culturas exigem maior controle sobre plantas espontâneas. 
Um elemento de forte conflito entre os estilos de agricultura praticados no PARC é decorrente da exigência da implantação de barreira vegetal, ou cortina verde, para reduzir o contato entre as áreas cultivadas com agrotóxicos e os "lotinhos". A barreira vegetal é constituída por um cordão de plantas que reduz as trocas entre duas áreas de produção agropecuária, no caso especifico, especialmente a passagem de agrotóxicos e a contaminação genética. A implantação das barreiras vem sendo discutida entre as famílias do PARC, a partir da exigência de sua implantação, pela rede Ecovida, para a obtenção da certificação orgânica da produção dos "lotinhos".

Muitas das famílias ainda não realizaram a implantação das barreiras, o que tem gerado influências na produção das outras famílias e complicado o processo de certificação. Isso tem causado tensionamentos internos no PARC, dado que se observou a significativa ausência dessas barreiras nas áreas. Além disso, os relatos apontam que muitas pulverizações realizadas nos dois alqueires prejudicam as barreiras vegetais já existentes, o que também gera atritos, além de prejudicar a produção dos "lotinhos".

A implantação das barreiras não é um processo aleatório e requer planejamento e orientação técnica. Uma das funções das barreiras vegetais pode ser a de funcionar como quebra vento, que segundo França e Oliveira (2010), gera inquestionáveis benefícios econômicos aos agricultores. Também Schoffel (2009) e Leal (1986) apontam as vantagens ambientais e econômicas do uso dessas técnicas, desde que devidamente orientadas do ponto de vista técnico, o que não tem ocorrido. Isso remete a outro limite importante percebido no processo de transição agroecológica no PARC.

Por fim, também é importante destacar a grande lacuna existente em termos de acompanhamento técnico, para dar suporte e orientação especializada ao processo de transição agroecológica, junto as famílias do PARC. A contribuição de pesquisadores e técnicos nos processos de transição agroecológica em assentamentos, em uma perspectiva metodológica participativa e dialógica, é destacada por Wigg et al. (2016) e Lopes et al. (2017). No caso do PARC, a passagem da condição de pré-assentamento para assentamento poderá melhorar a disponibilidade desses serviços de apoio, de forma que o processo de transição agroecológica iniciado pelas famílias através da experiência dos "lotinhos", será facilitada e também facilitadora do avanço da agroecologia no conjunto do futuro assentamento.

\section{CONSIDERAÇÕES FINAIS}

O presente artigo analisa a experiência de transição agroecológica no PARC, em Cascavel - PR, onde se evidencia a coexistência de distintos modelos e estilos de agricultura. Pode-se observar a presença de estilos de agricultura associados 
tanto ao modelo do agronegócio, mais evidente na área dos dois alqueires, como da agroecologia, mais evidente nos "lotinhos", o que tem sido fonte de alguns conflitos internos. Nos dois alqueires, os estilos de agricultura são centrados em monocultivos comerciais, baseados em padrão tecnológico que gera dependência externa aos agricultores. Nos "lotinhos", os estilos de agricultura são mais diversificados, voltados para a alimentação familiar e menos dependentes de insumos externos e do mercado. As famílias estão empenhadas no processo de transição agroecológica, desenvolvendo experimentação e adoção de práticas agroecológicas, além da realização de troca de saberes. Pode-se afirmar que a consolidação e expansão da agroecologia é impulsionada pela experiência dos "lotinhos", todavia, até o momento, não se observa o transbordamento da agroecologia para a área dos dois alqueires.

\section{REFERÊNCIAS}

ALTIERI, Miguel. Agroecologia, agricultura camponesa e soberania alimentar. Revista NERA, n. 16, p. 22-32, Jan./Jun. 2010.

. Agroecologia: bases científicas para uma agricultura sustentável. 3. ed. São Paulo, Rio de Janeiro: Expressão Popular, AS-PTA, 2012, p.400.

BARCELLOS, Sérgio Botton. A formação do discurso da agroecologia no MST. 2010. 139 p. Dissertação (Mestrado em Ciências Sociais) - Programa de PósGraduação em Desenvolvimento, Agricultura e Sociedade, Universidade Federal Rural do Rio de Janeiro, Seropédica, 2010.

CAPORAL, Francisco Roberto. Em defesa de um Plano Nacional de Transição Agroecológica: compromisso com as atuais e nosso legado para as futuras gerações. 2009. Manuscrito.

CONTERATO, Marcelo Antônio; NIEDERLE, Paulo André; RADOMSKY, Guilherme; SCHNEIDER, Sergio. Mercantilização e mercados: a construção da diversidade da agricultura na ruralidade contemporânea. In: SCHNEIDER, S.; GAZOLLA, M. (Org.). Os atores do desenvolvimento rural: perspectivas teóricas e práticas. Porto Alegre: Editora da UFRGS, 2011. p. 67-89.

COSTABEBER, José Antônio. Transição agroecológica: do produtivismo à 
ecologização. In: CAPORAL, R, F. COSTABEBER, J, A. Agroecologia e a Extensão Rural: contribuições para a promoção do desenvolvimento rural sustentável. Porto Alegre: 2004. p. 17-48.

CARMO, Maristela Simões do; COMITRE, Valéria; BORSATTO, Ricardo; MOREIRA, Rodrigo; STAMATO, Beatriz. O diálogo necessário entre extensão rural e agroecologia. Revista Retratos de Assentamentos, v.18, n.1, p. 269-289, Jan./Jun. 2015.

DELGADO, Guilherme Costa. Do capital financeiro a economia do agronegócio. Porto Alegre: Editora UFRGS, 2012, p.142.

FOOD AND AGRICULTURE ORGANIZATION OF THE UNITED NATIONS - FAO. The State of Food Security and Nutrition in the World 2017. Building resilience for peace and food security. Roma: FAO, 2017, p.117.

FRANÇA, Francisco Cavalcante; OLIVEIRA, João Bosco de. Quebra-ventos na propriedade agrícola. Fortaleza: Secretaria de Recursos Hídricos, 2010, p.21.

GAZOLLA, Marcio; SCHNEIDER, Sergio. Cadeias curtas e redes agroalimentares alternativas. In.: GAZOLLA, M.; SCHNEIDER, S. (Orgs.). Cadeias curtas e redes agroalimentares alternativas: negócios e mercados da agricultura familiar. Porto Alegre: Editora da UFRGS, 2017, p. 9-24.

GLIESSMAN, Stephen R. Agroecologia: processos ecológicos em agricultura sustentável. Porto Alegre: Editora da Universidade - UFRGS, 2000.p.653.

GONÇALVES, Sérgio. Campesinato, resistência e emancipação: o modelo agroecológico adotado pelo MST no estado do Paraná. 2008. p.308. Tese (Doutorado em Geografia) - Programa de Pós-Graduação em Geografia, Universidade Estadual Paulista "Júlio de Mesquita Filho", Presidente Prudente, 2008.

. O modelo agroecológico adotado pelo MST no estado do Paraná. In: ENCONTRO NACIONAL DE GEOGRAFIAAGRÁRIA, XXI. 2012, Uberlândia. Anais... Uberlândia: UFU, 2012. p.1-21.

GUHUR, Dominique Michèle Perioto. Contribuições do diálogo de saberes 
à educação profissional em agroecologia no MST: desafios da educação do campo na construção do projeto popular. 2010. 267 p. Dissertação (Mestrado em Educação) - Programa de Pós-Graduação em Educação, Universidade Estadual de Maringá, Maringá, 2010.

LEAL, Alex Carneiro. Quebra-ventos arbóreos: aspectos fundamentais de uma técnica altamente promissora. Curitiba: IAPAR, 1986, p.28.

LEFF, Enrique. Agroecologia e saber ambiental. Revista Agroecologia e Desenvolvimento Rural e Sustentável, v.3, n.1, p. 36-51, jan./mar. 2002.

LEITE, Sérgio Pereira; MEDEIROS, Leonilde Servolo. Agronegócio. In: CALDART, R. S. et. al. (Orgs.). Dicionário da Educação do Campo. Rio de Janeiro/São Paulo: Escola Politécnica de Saúde Joaquim Venâncio, Expressão Popular, 2012, p. 81-87.

LONG, Norman. Sociología del desarrollo: una perspectiva centrada en el actor. México: Ciesas, 2007, p.499.

LONG, Norman; PLOEG, Jan Douwe Van Der. Heterogeneity, actor and structure: towards a reconstitution of the concept of structure. In: BOOTH, D. (Org.). Rethinking social development: theory, research and practice. Harlow: Longman, p. 62-90, 1994.

LOPES, Paulo Rogério; ARAÚJO, Keila Cássia Santos; SILVA, Roberta Cristina; SILVA, Jonas Pereira; BERGAMASCO, Sonia Maria Pessoa Pereira. Agroecologia e processos de transição no Assentamento Rural Santa Helena. Revista Retratos de Assentamentos, v.20, n.2, p. 125-148, jul./dez. 2017.

MARTINS, Adalberto Floriano Greco. A produção ecológica de arroz nos assentamentos da Região Metropolitana de Porto Alegre: territórios de resistência ativa e emancipação. 2017. p. 296. Tese (Doutorado em Geografia) Programa de Pós-Graduação em Geografia, Universidade Federal do Rio Grande do Sul, Porto Alegre, 2017.

A agroecologia na estratégia do MST como parte da contraposição ao agronegócio. In: SEMINÁRIO DA REGIÃO SUL SOBREAAGROECOLOGIA, X, 2013, São Miguel do Iguaçu. Manuscrito. 
MINAYO, Maria Cecília de Souza. Pesquisa social: teoria, método e criatividade. 31. Ed. Petrópolis: Vozes, 2012, p.108.

MOVIMENTO DOS TRABALHADORES RURAIS SEM TERRA - MST. Programa de Formação para a Cooperação e Organização dos Assentamentos. Cartilha de Apoio, I. São Paulo, MST, 2008.

NIEDERLE, Paulo André; ESCHER, Fabiano; CONTERATO, Marcelo Antônio. Estilos de agricultura: capturando a diversidade do rural contemporâneo. In: CONTERATO, M. et al. (Org.). Pesquisa em desenvolvimento rural: aportes teóricos e proposições metodológicas. Porto Alegre: Editora da UFRGS, 2014, p. 205-225.

PLOEG, Jan Douwe Van Der. Styles of farming: an introductory note on concepts and methodology. In: PLOEG, J. D. van der; LONG, A. Born from within. Assen: Van Gorcum, 1994, p.7-30.

. Camponeses e impérios alimentares: lutas por autonomia e sustentabilidade na era da globalização. Porto Alegre: Editora da UFRGS, 2008, p.372.

ROOS, Djoni. Contradições na construção dos territórios camponeses no Centro-Sul paranaense: territorialidades do agronegócio, subordinação e resistências. 2015. 392 p. Tese (Doutorado em Geografia) - Programa de PósGraduação em Geografia, Universidade Estadual Paulista “Júlio de Mesquita Filho", Presidente Prudente, 2015.

SAUER, Sérgio. Agricultura familiar versus agronegócio: a dinâmica sociopolítica do campo brasileiro. Brasília: Embrapa Informação Tecnológica, 2008, p. 73 .

SCHNEIDER, Sergio; ESCHER, Fabiano. El concepto de agricultura familiar en América Latina. In: CRAVIOTTI, C. (Org.). Agricultura familiar en Latinoamérica: continuidad, transformaciones y controversias. Buenos Aires: CICCUS, 2014, p. 25-56.

SCHOFFEL, Edgar Ricardo. Importância agroecológica dos ventos: quebraventos. Pelotas: UFPel, 2009. p.19. 
WANDERLEY, Maria de Nazareth Baudel. Agricultura familiar e campesinato: rupturas e continuidade. Estudos Sociedade e Agricultura, n. 21, p. 42-61, out. 2003.

WIGG, David; VIEIRA, Fernanda Maria; QUINTANS, Mariana Trotta; SOUZA, Natália Almeida; SILVA, Nivia Regina; LUSTOSA, Raoni Amaral. Semeando novos tempos? Reforma agrária e agroecologia um diálogo possível e necessário - análise a partir do estudo de caso do PDS Osvaldo de Oliveira no Rio de Janeiro. Revista Retratos de Assentamentos, v.19, n.1, p. 117-147, jan./jun. 2016.

YIN, Robert K. Estudo de caso: planejamento e métodos. 2. ed. Porto Alegre: Bookman, 2001, p.205. 